\title{
Effects of exercise dose on endogenous estrogens in postmenopausal women: a randomized trial
}

\author{
Christine M Friedenreich ${ }^{1,2}$, Heather K Neilson', Qinggang Wang', Frank Z Stanczyk ${ }^{3}$, \\ Yutaka Yasui ${ }^{4}$, Aalo Duha ${ }^{5}$, Sarah MacLaughlin', Ciara Kallal ${ }^{6}$, Cynthia C Forbes ${ }^{6}$ and \\ Kerry S Courneya ${ }^{6}$ \\ 'Department of Cancer Epidemiology and Prevention Research, CancerControl Alberta, Alberta Health Services, \\ 2210 2nd Street Southwest, Calgary, Alberta, Canada T2S 3C3 \\ ${ }^{2}$ Departments of Oncology and Community Health Sciences, Cumming School of Medicine, University of Calgary, \\ Calgary, Alberta, Canada \\ ${ }^{3}$ Keck School of Medicine, University of Southern California, Los Angeles, California, USA \\ ${ }^{4}$ School of Public Health, University of Alberta, Edmonton, Alberta, Canada \\ ${ }^{5}$ Cross Cancer Institute, CancerControl Alberta, Alberta Health Services, Edmonton, Alberta, Canada \\ ${ }^{6}$ Faculty of Physical Education and Recreation, University of Alberta, Edmonton, Alberta, Canada
}

\author{
Correspondence \\ should be addressed \\ to C M Friedenreich \\ Email \\ christine.friedenreich@ \\ albertahealthservices.ca
}

\begin{abstract}
Exercise dose comparison trials with biomarker outcomes can identify the amount of exercise required to reduce breast cancer risk and also strengthen the causal inference between physical activity and breast cancer. The Breast Cancer and Exercise Trial in Alberta (BETA) tested whether or not greater changes in estradiol $\left(E_{2}\right)$, estrone, and sex hormone-binding globulin (SHBG) concentrations can be achieved in postmenopausal women randomized to 12 months of HIGH (300 min/week) vs MODERATE (150 min/week) volumes of aerobic exercise. BETA included 400 inactive postmenopausal women aged $50-74$ years with BMI of $22-40 \mathrm{~kg} / \mathrm{m}^{2}$. Blood was drawn at baseline and 6 and 12 months. Adiposity, physical fitness, diet, and total physical activity were assessed at baseline and 12 months. Intention-to-treat analyses were performed using linear mixed models. At full prescription, women exercised more in the HIGH vs MODERATE group (median min/week (quartiles 1,3): 253 (157 289) vs 137 (111 150); $P<0.0001)$. Twelve-month changes in estrogens and SHBG were $<10 \%$ on average for both groups. No group differences were found for $E_{2}$, estrone, SHBG or free $E_{2}$ changes (treatment effect ratios $(95 \% \mathrm{Cl})$ from linear mixed models: 1.00 (0.96-1.06), 1.02 (0.98-1.05), 0.99 (0.96-1.02), $1.01(0.95,1.06)$, respectively, representing the HIGH:MODERATE ratio of geometric mean biomarker levels over 12 months; $n=382$ ). In per-protocol analyses, borderline significantly greater decreases in total and free $\mathrm{E}_{2}$ occurred in the HIGH group. Overall, no dose effect was observed for women randomized to 300 vs $150 \mathrm{~min} /$ week of moderate to vigorous intensity exercise who actually performed a median of 253 vs $137 \mathrm{~min} /$ week. For total and free E2, the lack of differential effect may be due to modest adherence in the higher dose group.
\end{abstract}

\author{
Key Words \\ - exercise \\ - estrogens \\ sex hormone-binding \\ globulin \\ - postmenopause \\ - breast cancer
}




\section{Introduction}

Inadequate physical activity is one of the few known modifiable risk factors for postmenopausal breast cancer (World Cancer Research Fund and American Institute for Cancer Research 2007, 2010). Minimum physical activity recommendations for cancer prevention include $150 \mathrm{~min}$ /week (World Health Organization 2011, Kushi et al. 2012) or $210 \mathrm{~min} /$ week of moderate-intensity activity (World Cancer Research Fund and American Institute for Cancer Research 2007), $150 \mathrm{~min} /$ week of moderatevigorous activity (Canadian Society for Exercise Physiology 2011), and $75 \mathrm{~min} /$ week of vigorous activity (World Health Organization 2011, Kushi et al. 2012). Whether or not these recommendations are optimal for postmenopausal breast cancer prevention, however, is unclear (Hastert et al. 2013). Recently a meta-analysis estimated a $5 \%$ decrease in breast cancer risk with every $2 \mathrm{~h} /$ week increment in moderate-vigorous recreational activity (Wu et al. 2013). Such analyses of observational data could be misleading, however, because of inconsistent methods for defining physical activity across studies, physical activity measurement error, and confounding by other factors. Alternatively, exercise trials with biomarker endpoints provide important evidence (Rundle 2005).

Endogenous estrogens are convincing biomarkers of postmenopausal breast cancer risk (Key et al. 2002, Woolcott et al. 2010, James et al. 2011, Tworoger et al. 2011, 2014, Zhang et al. 2013, Endogenous Hormones and Breast Cancer Collaborative Group 2015). One pooled analysis showed an approximately twofold higher risk of postmenopausal breast cancer for women categorized in the highest vs lowest quintiles of circulating estradiol $\left(\mathrm{E}_{2}\right)$ and estrone concentrations respectively (Endogenous Hormones and Breast Cancer Collaborative Group 2015). Most randomized controlled trials (RCTs) comparing 3-12 month exercise prescriptions of 150-225 min/week vs no exercise in postmenopausal women have improved circulating concentrations of $\mathrm{E}_{2}$, estrone, and sex hormone-binding globulin (SHBG) on average by $2-13 \%$ (Figueroa et al. 2003, Copeland \& Tremblay 2004, McTiernan et al. 2004, Orsatti et al. 2008, Monninkhof et al. 2009, Friedenreich et al. 2010, Yoo et al. 2010, Campbell et al. 2012, Kim \& Kim 2012). Additional mechanisms are hypothesized to relate physical activity to breast cancer risk (reviewed in Neilson et al. (2014)); however, with the exception of body fat (World Cancer Research Fund and American Institute for Cancer Research 2007, 2010 Suzuki et al. 2009), these pathways are not as clearly established as for sex hormones.
Previously in the Alberta Physical Activity and Breast Cancer Prevention (ALPHA) trial, we randomized 320 postmenopausal women to $225 \mathrm{~min} /$ week of aerobic exercise or usual inactivity over 12 months. In the exercise group, average reductions in circulating $\mathrm{E}_{2}$ and free $\mathrm{E}_{2}$, and the average increase in SHBG, were significantly greater than controls; there was no significant difference for estrone changes (Friedenreich et al. 2010). Furthermore in an exploratory analysis, favorable dose-response trends were found between average $\mathrm{E}_{2}$ changes (but not estrone) and exercise adherence: $<150,150-225$ and $>225 \mathrm{~min} /$ week. However, the ALPHA trial was not designed to examine dose-response trends. Our doseresponse analysis was based on self-selected adherence levels, and we had insufficient statistical power for detecting significant differences across adherence strata.

In the Breast Cancer and Exercise Trial in Alberta (BETA), we aimed to formally test the dose-response effects of exercise by examining whether or not greater changes in $\mathrm{E}_{2}$, estrone, and SHBG concentrations would be achieved in postmenopausal women randomized to a HIGH (300 min/week) vs MODERATE (150 min/week) volume aerobic exercise prescription over 12 months.

\section{Materials and methods}

\section{The BETA trial}

Detailed methods for the BETA trial were published previously (Friedenreich et al. 2014). The BETA trial was a two-centre, two-armed randomized controlled exercise intervention trial in Calgary and Edmonton, Alberta, conducted between June 2010 and June 2013. The overall aim of the study was to examine the dose-response effects of aerobic exercise on adiposity and a variety of proposed blood biomarkers of postmenopausal breast cancer risk. We hypothesized that more favorable biomarker improvements would occur in women prescribed a higher vs moderate volume of aerobic exercise. The focus of the current report is on endogenous sex hormones, which were secondary outcomes from the trial. Total body fat change was the primary outcome and is described in a separate report (Friedenreich et al. 2015).

\section{Participants}

Eligible women were postmenopausal, age 50-74 years, BMI $22-40 \mathrm{~kg} / \mathrm{m}^{2}$ and moderately inactive $(\leq 120 \mathrm{~min} /$ week

Published by Bioscientifica Ltd. 
of self-reported moderate-intensity recreational activity or $\leq 3$ days/week for $<30 \mathrm{~min} /$ session maximum; estimated $\mathrm{VO}_{2 \max } \leq 34.5 \mathrm{ml} / \mathrm{kg} \min$ or $34.6 \mathrm{ml} / \mathrm{kg} \min \leq \mathrm{VO}_{2 \max }$ $\leq 37.0 \mathrm{ml} / \mathrm{kg} \mathrm{min}$ and 7-day accelerometer count $<10000$ steps/day), with no previous cancer diagnosis except non-melanoma skin cancer and no major co-morbid condition or recent major reconstructive surgery. Women were able to maintain acceptable heart and lung function in a sub-maximal treadmill test, were non-users of exogenous hormones or drugs affecting estrogen metabolism and non-smokers, consumed less than or equal to two drinks of alcohol/day over the past year, were English-speaking, resided in Calgary or Edmonton with access to our fitness facility, were not intending to be away more than 4 weeks consecutively and 8 weeks total over the next year and not on or planning a weight loss program. The study protocol was approved by the Alberta Cancer Research Ethics Committee and the Conjoint Health Research Ethics Board of the University of Calgary and the Health Research Ethics Board of the University of Alberta. All participants provided written informed consent after full explanation of the purpose of the trial and trial procedures. Trial registration on ClinicalTrials.gov was initiated prior to analyzing any primary or secondary outcomes.

\section{Randomization}

Four hundred postmenopausal women were randomly assigned in a 1:1 ratio to either a 12-month aerobic exercise intervention of HIGH (300 min/week) or MODERATE (150 min/week) volume. Randomization was stratified by the study centre and BMI $(<28.8, \geq 28.8)$. Blocking was used within strata with block sizes of four or six to ensure balance between the two arms with respect to the number of participants. The random allocation sequence was generated via user-defined functions within R Software (version 2.11) (R Core Team 2010). Allocations were concealed in numbered envelopes that were prepared by a staff member unrelated to the study team.

\section{Measurements}

Demographic and baseline health information was collected by a questionnaire when ascertaining eligibility. Past year total physical activity, which was the sum of all occupational, household, and recreational activities as well as walking or bicycling to/from work (Friedenreich et al. 2006), and past year usual diet (Csizmadi et al. 2007) were self-reported at baseline and 12 months. All activities reported in the Past Year Total Physical Activity
Questionnaire were converted into the metabolic equivalent of task (MET) h/week per year using the Compendium of Physical Activities (Ainsworth et al. 2011). Additionally at baseline and 12 months, submaximal fitness tests were conducted using the same protocols and equipment at both study centers. In Edmonton, fitness tests took place at the Cross Cancer Institute and the Behavioural Medicine Fitness Centre at the University of Alberta. Calgary participants were assessed at the Tom Baker Cancer Centre and the Faculty of Kinesiology, University of Calgary. Fitness testing followed the multistage modified Balke treadmill test protocol (Pollock et al. 1982). Testing was complete once a participant reached $85 \%$ of her age-predicted maximum heart rate or volitional exhaustion. Each participant's predicted $\mathrm{VO}_{2 \max }$ was estimated using the multistage model and the American College of Sports Medicine metabolic equations for maximum oxygen consumption (American College of Sports Medicine 2000).

Anthropometric measurements were taken at the same time as fitness testing. Standing height and weight were measured by research staff using a balance beam scale and stadiometer. Measures were taken in duplicate and then averaged; if the two measures were discrepant, a third measure was taken. Waist circumference was determined using an anthropometric measuring tape and the National Institutes for Health protocol (National Institutes of Health 1998, Canadian Society for Exercise Physiology 2003). Full body dual-energy $x$-ray absorptiometry (DXA) scans were taken using a Hologic Discovery A DXA system and Hologic QDR Software (Hologic Inc., Bedford, MA, USA) or a GE Healthcare Lunar Prodigy DXA and GE Healthcare enCORE Software (GE Medical Systems Lunar, Madison, WI, USA) to assess lean mass and total fat mass. Percent body fat was calculated as $100 \% \times($ fat mass/ (fat mass + lean mass)).

\section{Intervention}

The intervention began with a goal to reach full exercise prescription within the first 12 weeks by gradually increasing exercise volume. As previously described (Friedenreich et al. 2014), the goal by week 13 was to attain 5 days/week of aerobic exercise for $30 \mathrm{~min}$ (MODERATE) or $60 \mathrm{~min}$ (HIGH) per session achieving 60-80\% maximum heart rate reserve for at least half of each workout. The individual target intensity ranged from $60-70 \%$ to $70-80 \%$ heart rate reserve depending on ability level. To confirm this intensity, women were asked to wear Polar FT4 heart rate monitors (Polar Electro, Lachine, QC,

Published by Bioscientifica Ltd. 
Canada) during supervised and unsupervised sessions. Between weeks 13 and 52, women were prescribed supervised sessions at an exercise facility 3 days/week and unsupervised home-based exercise 2 days/week. Supervised sessions took place at the Westside Recreation Centre (Calgary) and the Behavioural Medicine Fitness Centre, University of Alberta (Edmonton). Home-based sessions were initially prescribed once weekly (weeks 5-8) and later increased to twice weekly. Adherence was monitored using weekly exercise logs maintained by participants, documenting activity types, total exercise duration, exercise 'time in zone,' average heart rate, and a Borg Rating of Perceived Exertion (Borg 1998). Exercise trainers kept separate logs of the same exercise variables as well as any absences from supervised sessions. Participants were asked not to change their usual diet.

\section{Endogenous sex hormones}

Blood samples were drawn at baseline and 6 and 12 months after a minimum $10 \mathrm{~h}$ fast and complete abstinence from exercise and alcohol intake for $24 \mathrm{~h}$. If a woman was $<55$ years of age with no bilateral oophorectomy or menopausal status was uncertain, a follicle-stimulating hormone test confirmed eligibility. All blood samples were stored at $-86^{\circ} \mathrm{C}$ in the Alberta Cancer Research Biorepository in Calgary. $\mathrm{E}_{2}$ and estrone were measured by radioimmunoassay with preceding organic solvent extraction and Celite column partition chromatography steps. Assay sensitivities were 2 and $4 \mathrm{pg} / \mathrm{ml}$, respectively, and inter-assay coefficients of variation (CV) were 9-14\%. SHBG was measured using solid-phase, two-site chemiluminescent immunometric assays on the Immulite analyzer (Siemens Healthcare Diagnostics, Deerfield, IL, USA); assay sensitivity was $1 \mathrm{nmol} / \mathrm{l}$ and the inter-assay CV was $<10 \%$. Appropriate quality control samples were used to monitor assay reliability. Each participant's baseline and 6 and 12 month samples were analyzed in the same batch and each batch included an equal number of MODERATE and HIGH blood samples. Blind duplicates were included in and between batches to estimate CVs. All lab personnel were blinded to the intervention assignment.

\section{Sample size/power considerations}

Sample size calculations were based on the standard formula for two-sample mean comparisons (Rosner 2011) with $\alpha=0.05$ (two-sided) for comparing mean 12-month biomarker changes (log-transformed) with no adjustment for baseline values. ALPHA trial results provided standard deviation estimates and yardstick intervention effects. A sample size of 150 participants per group was initially selected allowing $95 \%$ power to detect 3 and $4 \%$ group differences in 12-month changes in percent body fat and total fat mass, respectively, which were primary outcomes in the trial. Allowing $10 \%$ loss to follow-up, a group size of 165 was planned. However, due to a high volunteer response, the sample size was increased to 200 per group.

\section{Statistical analysis}

Group differences in demographic and lifestyle information and biomarker concentrations at baseline were compared using a $\chi^{2}$ test for categorical data, $t$-test for continuous data and Wilcoxon rank-sum test for nonnormally distributed continuous data. Because all biomarker data were non-normally distributed, subsequent analyses of a more analytic (rather than descriptive) nature were performed on log-transformed values. Sex hormone changes in the two arms were compared in an intentionto-treat analysis using linear mixed models that accounted for repeated measures of sex hormone concentrations at 6 and 12 months and adjusted for baseline levels of the biomarker of interest as a covariate. Treatment effect ratios, also referred to as 'treatment effects' or 'dose effects' in this report, were calculated from these models and represented the HIGH:MODERATE ratio of geometric mean biomarker levels over 12 months (reflecting changes from baseline to 6 and 12 months). A treatment effect ratio $<1.0$ indicated lower biomarker concentrations in the HIGH exercise group compared with the MODERATE group at 6 and 12 months; a ratio $>1.0$ indicated lower biomarker concentrations in the MODERATE exercise group; and a ratio equal to 1.0 indicated no difference in biomarker concentrations between exercise groups.

In addition, we repeated our intention-to-treat analysis stratified by a priori effect modifiers: baseline BMI and study site (Calgary, Edmonton) and also by baseline physical fitness level in a post hoc analysis (given effect modification by this variable in the ALPHA trial (Friedenreich et al. 2011)). Furthermore, a sensitivity analysis was performed to account for possible sex hormone hemodilution that might occur as a result of a larger body surface area in obese women (Yang et al. 2011). In so doing, we repeated the intention-to-treat analysis, with and without stratification by baseline BMI, using sex hormone mass as the unit of analysis. Sex hormone mass was calculated as $(\log ($ sex hormone concentration $) \times$ $\left(\left(\right.\right.$ weight $(\mathrm{kg})^{0.425} \times$ height $\left.\left.\left.(\mathrm{m})^{0.725} \times 0.2025\right) \times 1.395\right)\right)$ as

Published by Bioscientifica Ltd. 
described previously (Grubb et al. 2009, Yang et al. 2011) using a plasma volume (L) formula (i.e., body surface area $\left.\left(\mathrm{m}^{2}\right) \times 1.395\right)$ derived for women (Pearson et al. 1995). An additional sensitivity analysis was performed removing non-compliant participants who changed energy intake $\geq 1000 \mathrm{kcal} /$ day between baseline and 12 months according to Diet History questionnaires.

In addition, a per-protocol analysis was conducted for women who were $90-100 \%$ adherent in the MODERATE group (135-150 min/week) or $\geq 90 \%$ adherent in the HIGH group ( $\geq 270 \mathrm{~min} /$ week) on average between weeks 13 and 52 (after the 12-week ramp-up period) according to exercise logs. Furthermore an exploratory analysis was performed, categorizing women by quintiles of total exercise duration without regard to group randomization. The ratio of geometric means (12 months:baseline) was calculated for each quintile and statistical significance was determined from linear models adjusted for the baseline level of the biomarker of interest. Tests for linear trend treated categories as a continuous variable. Moreover, a perprotocol analysis was carried out stratifying by time in zone (average, weeks 13-52) to explore the possibility of enhanced dose effects when exercise was mainly of high intensity. Finally, Spearman correlation coefficients $\left(r_{\mathrm{s}}\right)$ were used to describe relations between 12-month changes in each biomarker and hypothesized mediators of change (changes in $\mathrm{VO}_{2 \max }$ and adiposity respectively) (Friedenreich et al. 2011). All statistical tests were twosided with a 0.05 level of significance. Analyses were conducted using SAS version 9.2 (SAS Institute, Cary, NC, USA).

\section{Results}

A total of 400 women were randomized (Fig. 1) as described previously (Friedenreich et al. 2015). Baseline characteristics pertaining to the sex hormones analysis are described in Table 1 . At baseline, 22, 40, and 38\% of women in the HIGH volume group were BMI $<25 \mathrm{~kg} / \mathrm{m}^{2}$, $25 \leq \mathrm{BMI}<30 \mathrm{~kg} / \mathrm{m}^{2}$ and $\mathrm{BMI} \geq 30 \mathrm{~kg} / \mathrm{m}^{2}$, respectively, and similarly for the MODERATE group (19, 42, and 39\% respectively). Participants on average were younger postmenopausal women and overweight; most had postsecondary education, were not employed full-time and self-identified as white. There were no group differences at baseline except for average SHBG levels, which were significantly higher in the HIGH volume group. Fourteen women dropped out; nine from the MODERATE arm and five from the HIGH arm (Fig. 1). An additional four women

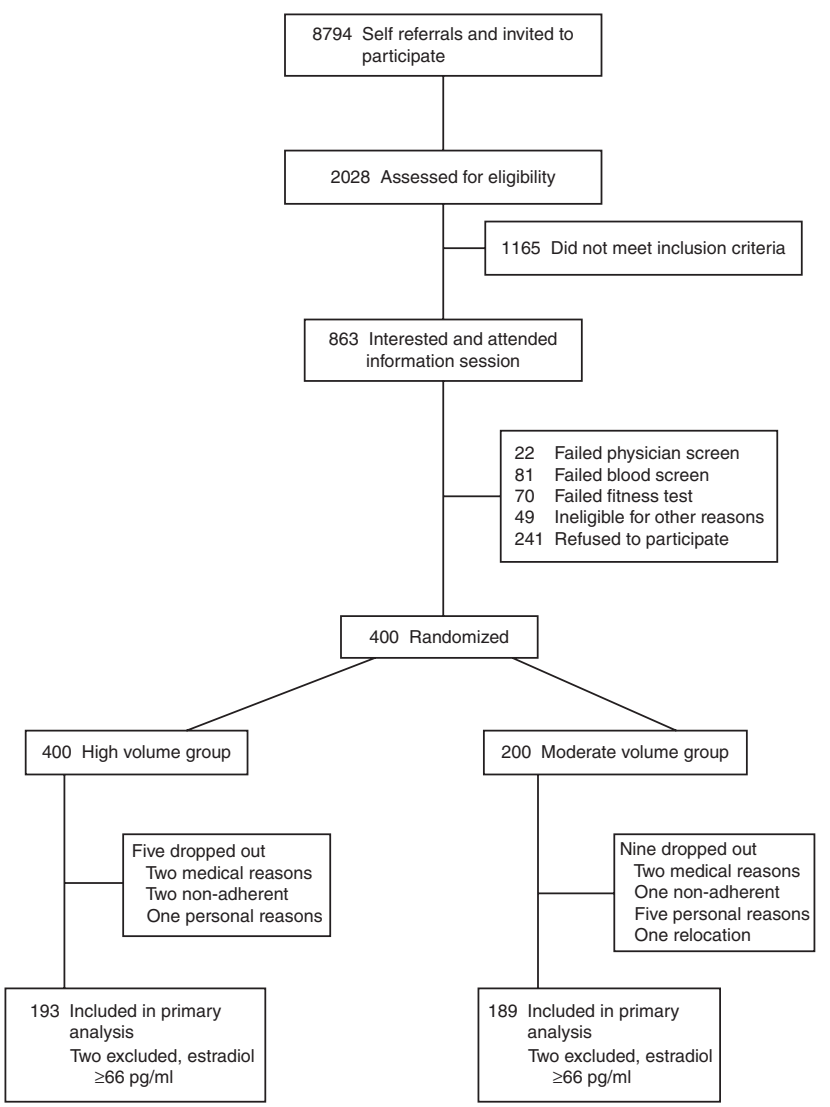

Figure 1

CONSORT diagram: Flow of participants through the BETA trial, Alberta, Canada, 2010-2013.

with total $\mathrm{E}_{2} \geq 66 \mathrm{pg} / \mathrm{ml}$ were suspected as perimenopausal or using estrogen treatment and were therefore excluded. No serious adverse events were reported during the trial.

Some exercise adherence data from BETA have been described previously (Friedenreich et al. 2015). For women included in the sex hormones analysis, those in the HIGH vs MODERATE group recorded more exercise on average $(P<0.0001$, two-sample $t$-test $)$, with 12 -month median (quartiles 1,3) adherence values of 228 (156 262) and 129 (106 138) min/week, respectively. Between weeks 13 and 52 (at full prescription after the 12-week ramp-up period), median adherence was 253 (157 289) vs 137 (111 150) min/week, and median time in zone was 128 (66 185) vs 88 (54 115) min/week, respectively, for the HIGH and MODERATE groups $(P<0.0001)$. Based on the Past Year Total Physical Activity Questionnaire (Friedenreich et al. 2006), usual recreational activity increased by 4.0 and $2.0 \mathrm{~h} /$ week (240 and $120 \mathrm{~min} /$ week) for $\mathrm{HIGH}$ and MODERATE groups, respectively $(P<0.0001$; Table 2$)$. Women in the HIGH group on average experienced

Published by Bioscientifica Ltd. 
Table 1 Baseline characteristics of randomized participants in the BETA trial, Alberta, Canada, 2010-2013

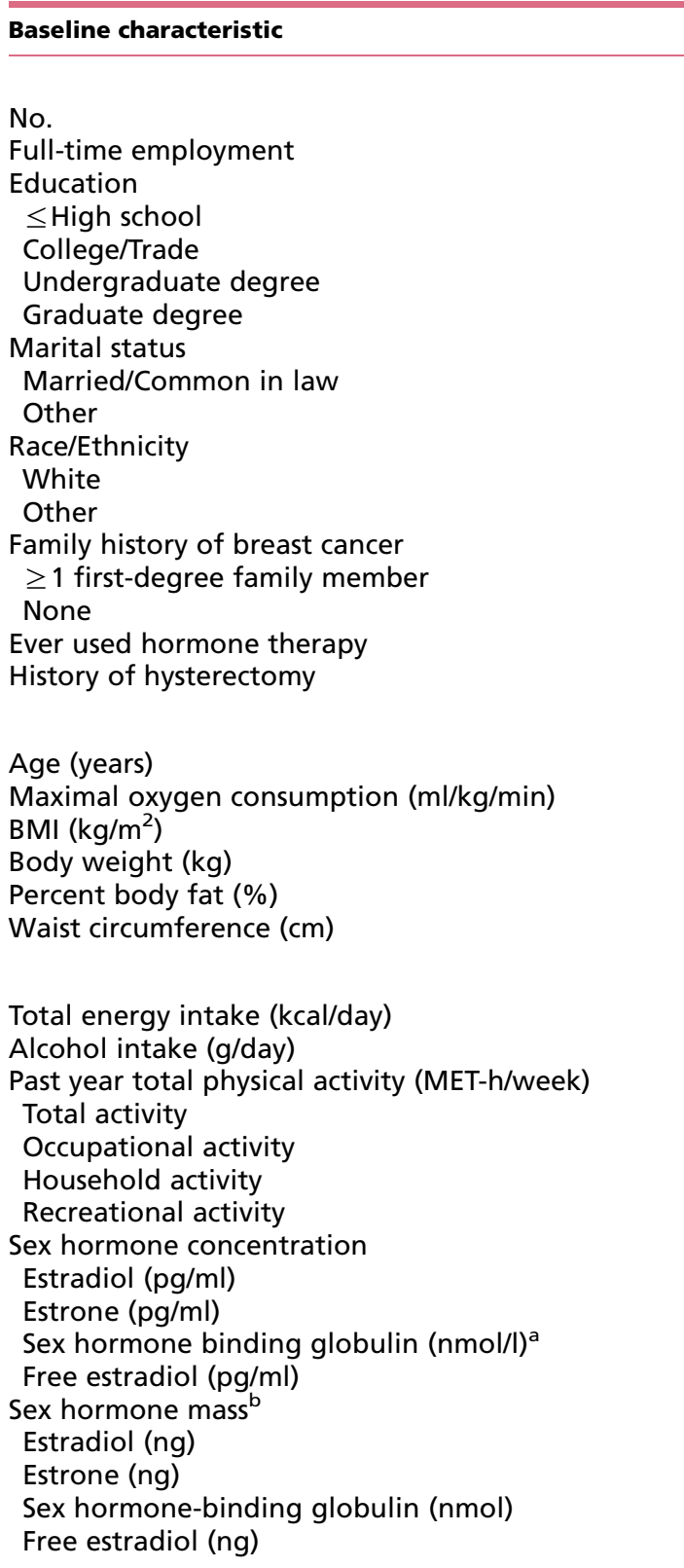

\begin{tabular}{|c|c|}
\hline Moderate & High \\
\hline$n(\%)$ & $n(\%)$ \\
\hline 200 & 200 \\
\hline $59(30)$ & $71(36)$ \\
\hline $45(23)$ & $45(23)$ \\
\hline $63(32)$ & $58(29)$ \\
\hline $54(27)$ & $59(30)$ \\
\hline $38(19)$ & $38(19)$ \\
\hline $139(70)$ & $136(68)$ \\
\hline $61(30)$ & $64(32)$ \\
\hline $186(93)$ & $172(86)$ \\
\hline $14(7)$ & $28(14)$ \\
\hline $39(20)$ & $33(17)$ \\
\hline $161(80)$ & $166(83)$ \\
\hline $55(28)$ & $62(31)$ \\
\hline $36(18)$ & $44(22)$ \\
\hline Mean \pm s.D. & Mean \pm s.D. \\
\hline $59.5 \pm 5.1$ & $59.4 \pm 4.8$ \\
\hline $26.8 \pm 5.0$ & $26.7 \pm 5.0 \pm 5.3$ \\
\hline $29.4 \pm 4.4$ & $29.1 \pm 4.4$ \\
\hline $77.4 \pm 13.0$ & $77.3 \pm 13.0$ \\
\hline $40.7 \pm 5.9$ & $40.5 \pm 5.8$ \\
\hline $98.6 \pm 10.8$ & $98.7 \pm 11.0$ \\
\hline Median (quartiles 1,3) & Median (quartiles 1,3) \\
\hline $1414(1112,1789)$ & $1379(1001,1797)$ \\
\hline $2.4(0.7,7.8)$ & $3.0(0.9,6.4)$ \\
\hline $90.6(60.6,121.9)$ & $89.0(62.2,115.8)$ \\
\hline $25.9(4.5,55.2)$ & $34.2(2.6,56.3)$ \\
\hline $41.0(27.0,60.6)$ & $40.4(28.3,60.1)$ \\
\hline $7.6(2.3,13.0)$ & $6.9(2.4,13.3)$ \\
\hline $9.7(7.6,12.9)$ & $9.4(7.3,12.2)$ \\
\hline $39.0(30.9,47.3)$ & $37.0(30.7,43.7)$ \\
\hline $42.7(32.8,59.7)$ & $46.1(34.7,65.4)$ \\
\hline $0.22(0.17,0.32)$ & $0.21(0.15,0.29)$ \\
\hline $24.0(18.4,34.4)$ & $23.1(17.9,31.3)$ \\
\hline $97.8(75.5,126.5)$ & $92.3(75.2,113.8)$ \\
\hline $106.8(84.5,145.5)$ & $122.4(89.7,164.8)$ \\
\hline $0.57(0.43,0.81)$ & $0.53(0.39,0.75)$ \\
\hline
\end{tabular}

${ }^{a}$ There were no statistically significant differences at baseline between HIGH and MODERATE groups for these variables except for sex hormone binding globulin, $P=0.04$

${ }^{5}$ Estimated as $\left(\right.$ log $($ sex hormone concentration $) \times\left(\left(\right.\right.$ weight $(\mathrm{kg})^{0.425} \times$ height $\left.\left.\left.(\mathrm{m})^{0.725} \times 0.2025\right) \times 1.395\right)\right)$ as described previously (Grubb et al. 2009 , Yang et al. 2011) using a plasma volume (L) formula (i.e., body surface area $\left.\left(\mathrm{m}^{2}\right) \times 1.395\right)$ derived for women (Pearson et al. 1995).

significantly greater reductions in percent body fat compared with the MODERATE group (Friedenreich et al. 2015). On average, total energy intake decreased significantly in the MODERATE group over 12 months, but not significantly more than in the HIGH group (Table 2).

At 6 and 12 months, all biomarker changes were $<10 \%$ (Table 3) and, unexpectedly, were more favorable for the MODERATE vs HIGH volume group. However, results from linear mixed models suggested no significant group differences with respect to biomarker changes, with all treatment effect ratios approximately equal to 1.0. Stratifying the results by baseline BMI, study site, or estimated $\mathrm{VO}_{2 \max }$ still resulted in non-significant dose effects for all biomarkers except SHBG, which varied by baseline BMI. Specifically, obese women experienced significantly greater SHBG increases with the HIGH 
Table 2 Physical activity ${ }^{a}$, fitness, diet, and adiposity changes (12 months - baseline) by group assignment in the BETA trial, Alberta, Canada, 2010-2013

\begin{tabular}{l} 
Measure \\
\hline Total activity (h/week) \\
Total activity (MET-h/week) \\
Occupational activity (h/week) \\
Occupational activity (MET-h/week) \\
Household activity (h/week) \\
Household activity (MET-h/week) \\
Recreational activity (h/week) \\
Recreational activity (MET-h/week) \\
Maximal oxygen consumption \\
$\quad$ (ml/kg/min) \\
Total energy intake (kcal/day) \\
Alcohol intake (g/day) \\
Body weight $(\mathrm{kg})^{\mathrm{c}}$ \\
Percent body fat ${ }^{\mathrm{c}}$ \\
Waist circumference (cm)
\end{tabular}

\begin{tabular}{|c|c|c|}
\hline \multicolumn{3}{|c|}{ MODERATE } \\
\hline$n$ & Mean change & $95 \% \mathrm{Cl}$ \\
\hline 184 & 2.1 & $-0.2,4.4$ \\
\hline 184 & 16.7 & $9.4,23.9$ \\
\hline 184 & 0.8 & $-0.8,2.5$ \\
\hline 184 & 3.7 & $-1.2,8.5$ \\
\hline 184 & -0.7 & $-2.4,1.1$ \\
\hline 184 & -0.8 & $-6.1,4.5$ \\
\hline 184 & 2.0 & $1.4,2.5$ \\
\hline 184 & 13.8 & $11.4,16.3$ \\
\hline 175 & 4.0 & $3.3,4.8$ \\
\hline 184 & -79.1 & $-136.0,-21.9$ \\
\hline 184 & 0.0 & $-0.9,1.0$ \\
\hline 183 & -1.9 & $-2.4,-1.3$ \\
\hline 185 & -1.1 & $-1.5,-0.7$ \\
\hline 183 & -4.7 & $-5.6,-3.9$ \\
\hline
\end{tabular}

\begin{tabular}{ccc}
\hline & & HIGH \\
\cline { 1 - 2 }$\frac{n}{185}$ & & Mean change \\
\cline { 1 - 1 } 185 & & 26.8 \\
185 & & -0.03 \\
185 & & 2.0 \\
185 & & -0.8 \\
185 & & -1.7 \\
185 & & 4.0 \\
185 & & 26.5 \\
180 & & 5.0 \\
& & \\
189 & & -51.0 \\
189 & & 0.0 \\
190 & -2.6 \\
190 & -2.0 \\
190 & -6.0 \\
\hline
\end{tabular}

\begin{tabular}{|c|c|}
\hline $95 \% \mathrm{Cl}$ & Between-group $P^{b}$ \\
\hline $0.9,5.5$ & 0.51 \\
\hline $19.4,34.2$ & 0.05 \\
\hline$-1.8,1.7$ & 0.48 \\
\hline$-3.6,7.7$ & 0.67 \\
\hline$-2.3,0.8$ & 0.92 \\
\hline$-5.9,2.5$ & 0.78 \\
\hline $3.4,4.6$ & $<0.0001$ \\
\hline $23.6,29.4$ & $<0.0001$ \\
\hline $4.2,5.9$ & 0.09 \\
\hline$-108.0,5.9$ & 0.49 \\
\hline$-0.7,0.6$ & 0.88 \\
\hline$-3.2,-1.9$ & 0.11 \\
\hline$-2.5,-1.5$ & 0.003 \\
\hline$-7.1,-4.9$ & 0.06 \\
\hline
\end{tabular}

MET, metabolic equilvalent of task.

${ }^{a}$ Estimated using the Past Year Total Physical Activity Questionnaire (Friedenreich et al. 2006).

${ }^{b}$ Based on a two-sample $t$-test.

'Detailed analyses of adiposity change are described elsewhere (Friedenreich et al. 2015).

prescription (12-month increase of $13.1 \%$ vs $8.2 \%$ for the MODERATE group; between-group $P=0.03$ from linear mixed models), whereas non-obese women experienced significantly greater increases with the MODERATE prescription (12-month change of $10.6 \%$ vs $2.4 \%$ for the HIGH group; between-group $P=0.02$ ). Intention-to-treat and BMI-stratified results were essentially unchanged when based on biomarker mass instead of biomarker concentration. Results were also unchanged when ten women with 12 -month changes $\geq 1000 \mathrm{kcal} /$ day in dietary energy intake were excluded.

Scatter plots of individual biomarker changes against exercise adherence (data not shown) revealed non-adherence in some participants such that $24 \%$ of the women in the HIGH group $(n=48)$ exercised $\leq 150 \mathrm{~min} /$ week on average over 12 months; in the

Table 3 Changes in endogenous estrogen and SHBG concentrations over 12 months in the BETA trial, Alberta, Canada, 2010-2013

\begin{tabular}{|c|c|c|c|c|c|c|c|c|c|c|c|}
\hline \multirow[b]{2}{*}{ Sex hormone } & \multicolumn{2}{|c|}{ Baseline } & \multicolumn{3}{|c|}{6 months } & \multicolumn{3}{|c|}{12 months } & \multicolumn{2}{|c|}{ Treatment effect $^{a}$} & \multirow[b]{2}{*}{$\begin{array}{l}\text { Between- } \\
\text { group } P^{b}\end{array}$} \\
\hline & $\begin{array}{c}\text { Geometric } \\
\text { mean }\end{array}$ & $95 \% \mathrm{Cl}$ & $\begin{array}{c}\text { Geometric } \\
\text { mean }\end{array}$ & $95 \% \mathrm{Cl}$ & $\begin{array}{l}\text { Percent } \\
\text { change }^{c}\end{array}$ & $\begin{array}{c}\text { Geometric } \\
\text { mean }\end{array}$ & $95 \% \mathrm{Cl}$ & $\begin{array}{l}\text { Percent } \\
\text { change }^{c}\end{array}$ & $\begin{array}{c}\text { Ratio of } \\
\text { HIGH:MOD }\end{array}$ & $95 \% \mathrm{Cl}$ & \\
\hline \multicolumn{12}{|c|}{ Estradiol (pg/ml) } \\
\hline MODERATE & 9.9 & $9.3,10.5$ & 9.7 & $9.1,10.2$ & -2.4 & 9.5 & $8.9,10.1$ & -4.5 & 1.00 & $0.96,1.06$ & 0.90 \\
\hline $\mathrm{HIGH}$ & 9.4 & $8.9,9.9$ & 9.5 & $9.0,10.0$ & 0.4 & 9.1 & $8.6,9.6$ & -3.6 & & & \\
\hline \multicolumn{12}{|c|}{ Estrone (pg/ml) } \\
\hline MODERATE & 38.6 & $36.7,40.6$ & 38.2 & $36.3,40.2$ & -1.2 & 37.4 & $35.6,39.3$ & -3.2 & 1.02 & $0.98,1.05$ & 0.42 \\
\hline $\begin{array}{l}\mathrm{HIGH} \\
\mathrm{SHBG}(\mathrm{nmol} / \mathrm{l})\end{array}$ & 36.4 & $34.8,38.0$ & 36.8 & $35.1,38.5$ & 1.1 & 36.4 & $34.7,38.2$ & 0.1 & & & \\
\hline MODERATE & 43.2 & $40.6,46.0$ & 46.2 & $43.5,49.0$ & 6.8 & 47.4 & $44.6,50.4$ & 9.6 & 0.99 & $0.96,1.02$ & 0.58 \\
\hline $\mathrm{HIGH}$ & 47.6 & $44.7,50.8$ & 50.2 & $47.1,53.4$ & 5.3 & 50.7 & $47.7,53.9$ & 6.4 & & & \\
\hline \multicolumn{12}{|c|}{ Free estradiol (pg/ml) } \\
\hline MODERATE & 0.23 & $0.22,0.25$ & 0.22 & $0.21,0.24$ & -4.5 & 0.21 & $0.20,0.23$ & -7.5 & 1.01 & $0.95,1.06$ & 0.83 \\
\hline $\mathrm{HIGH}$ & 0.21 & $0.20,0.23$ & 0.21 & $0.20,0.22$ & -1.3 & 0.20 & $0.19,0.21$ & -5.5 & & & \\
\hline
\end{tabular}

SHBG, sex hormone binding globulin.

${ }^{a}$ HIGH:MODERATE ratio of geometric means for biomarker levels over 12 months, adjusted for biomarker level at baseline. A ratio $<1.0$ indicates lower biomarker concentrations in the HIGH exercise group at 6 and 12 months; a ratio $>1.0$ indicates lower biomarker concentrations in the MODERATE exercise group; a ratio equal to 1.0 indicates no difference in biomarker concentrations between the HIGH and MODERATE exercise groups. Sample sizes were $n=189$ for MODERATE and $n=193$ for HIGH groups.

${ }^{b} P$ for testing group difference over 12 months from the linear mixed model, adjusted for biomarker level at baseline.

'Percent hormone change at 6 or 12 months from baseline for that group. 
Table 4 Changes in endogenous estrogen and SHBG concentrations over 12 months in adherent women ${ }^{\mathrm{a}}$ in the BETA trial, Alberta, Canada, 2010-2013

\begin{tabular}{|c|c|c|c|c|c|c|c|c|c|c|c|}
\hline \multirow[b]{2}{*}{ Sex hormone } & \multicolumn{2}{|c|}{ Baseline } & \multicolumn{3}{|c|}{6 months } & \multicolumn{3}{|c|}{12 months } & \multicolumn{2}{|c|}{ Treatment effect $^{b}$} & \multirow[b]{2}{*}{$\begin{array}{l}\text { Between- } \\
\text { group } P^{c}\end{array}$} \\
\hline & $\begin{array}{c}\text { Geometric } \\
\text { mean }\end{array}$ & $95 \% \mathrm{Cl}$ & $\begin{array}{c}\text { Geometric } \\
\text { mean }\end{array}$ & $95 \% \mathrm{Cl}$ & $\begin{array}{l}\text { Percent } \\
\text { change }^{d}\end{array}$ & $\begin{array}{c}\text { Geometric } \\
\text { mean }\end{array}$ & $95 \% \mathrm{Cl}$ & $\begin{array}{l}\text { Percent } \\
\text { change }^{d}\end{array}$ & $\begin{array}{c}\text { Ratio of } \\
\text { HIGH:MOD }\end{array}$ & $95 \% \mathrm{Cl}$ & \\
\hline \multicolumn{12}{|c|}{ Estradiol (pg/ml) } \\
\hline MODERATE & 10.2 & $9.2,11.4$ & 10.2 & $9.1,11.3$ & -0.76 & 9.6 & $8.5,10.9$ & -6.2 & 0.93 & $0.86,1.01$ & 0.09 \\
\hline $\mathrm{HIGH}$ & 8.8 & $8.2,9.5$ & 8.7 & $8.0,9.4$ & -0.85 & 7.9 & $7.3,8.5$ & -10.6 & & & \\
\hline \multicolumn{12}{|c|}{ Estrone (pg/ml) } \\
\hline MODERATE & 38.7 & $35.3,42.3$ & 38.6 & $34.9,42.7$ & -0.13 & 36.9 & $33.6,40.7$ & -4.5 & 1.01 & $0.96,1.07$ & 0.66 \\
\hline $\mathrm{HIGH}$ & 34.6 & $32.4,36.9$ & 35.5 & $32.9,38.3$ & 2.6 & 33.6 & $31.5,36.0$ & -2.8 & & & \\
\hline \multicolumn{12}{|l|}{ SHBG (nmol/l) } \\
\hline MODERATE & 44.9 & $40.3,50.0$ & 47.6 & $42.9,52.9$ & 6.1 & 49.4 & $44.5,54.9$ & 10.1 & 1.02 & $0.96,1.08$ & 0.45 \\
\hline $\mathrm{HIGH}$ & 48.3 & $43.4,53.8$ & 53.2 & $47.8,59.1$ & 10.1 & 52.6 & $47.5,58.3$ & 9.0 & & & \\
\hline \multicolumn{12}{|c|}{ Free estradiol (pg/ml) } \\
\hline MODERATE & 0.24 & $0.21,0.27$ & 0.23 & $0.21,0.26$ & -2.7 & 0.21 & $0.19,0.24$ & -9.2 & 0.93 & $0.85,1.00$ & 0.06 \\
\hline $\mathrm{HIGH}$ & 0.20 & $0.18,0.22$ & 0.19 & $0.17,0.21$ & -4.2 & 0.17 & $0.16,0.19$ & -13.2 & & & \\
\hline
\end{tabular}

SHBG, sex hormone binding globulin.

Included the subgroup of women for whom, across weeks 13-52 (at full prescription), average adherence in the exercise logs was $90-100 \%$ in the MODERATE group (135-150 min/week; $n=57$ ) or $\geq 90 \%$ in the HIGH group (270-350 $\mathrm{min} / \mathrm{week} ; n=78)$.

${ }^{b}$ HIGH:MODERATE ratio of geometric means for biomarker levels over 12 months, adjusted for biomarker level at baseline. A ratio <1.0 indicates lower biomarker concentrations in the HIGH exercise group at 6 and 12 months; a ratio $>1.0$ indicates lower biomarker concentrations in the MODERATE exercise group; a ratio equal to 1.0 indicates no difference in biomarker concentrations between the HIGH and MODERATE exercise groups.

${ }^{c} P$ for testing group difference over 12 months from the linear mixed model, adjusted for biomarker level at baseline.

${ }^{d}$ Percent hormone change at 6 or 12 months from baseline for that group.

MODERATE group 3\% of the women exercised $>150 \mathrm{~min} /$ week. Therefore, a per-protocol analysis was done based on exercise minutes per week (Table 4). In the per-protocol sample, all biomarker 12-month changes were $<14 \%$ and treatment effect ratios were not significantly different from 1.00. However, total and free $\mathrm{E}_{2}$ reductions were slightly greater for the $\mathrm{HIGH}$ vs MODERATE group resulting in borderline significant dose effects (between-group $P=0.09$ and $P=0.06$ respectively). In an exploratory analysis, inverse doseresponse trends were found between decreasing total and free $\mathrm{E}_{2}$ concentrations and increasing quintiles of total exercise time (Table 5). The highest 12-month reductions in total and free $\mathrm{E}_{2}$ concentrations were -11.0 and $-13.7 \%$, respectively, for women with average adherence estimates $>245 \mathrm{~min} /$ week, although similar reductions were also observed in the second and third quartiles.

In a per-protocol analysis examining exercise intensity (Table 6), women who exercised $\geq 60 \%$ of their prescribed exercise duration in their target heart rate zone (i.e., at least $90 \mathrm{~min} /$ week in the MODERATE group or at least $180 \mathrm{~min} /$ week in the HIGH group time in zone) experienced stronger dose effects with respect to total and free $\mathrm{E}_{2}$ changes $(11.2-13.5 \%$ 12-month decreases in the HIGH group vs $2.3-5.6 \%$ in the MODERATE group; $P=0.03, P=0.01$ between groups for total and free $\mathrm{E}_{2}$, respectively). However, $\mathrm{E}_{2}$ was also reduced with less time in zone (12-month decreases of 10.1-12.9\% for the HIGH group; $14.9-17.2 \%$ for MODERATE). Among all participants, 12-month body weight changes correlated significantly with biomarker changes $\left(r_{\mathrm{s}}=0.21, P<0.0001\right.$ for total $\mathrm{E}_{2} ; r_{\mathrm{s}}=0.17, P<0.0009$ for estrone; $r_{\mathrm{s}}=-0.44$, $P<0.0001$ for SHBG; $r_{\mathrm{s}}=0.29, P<0.0001$ for free $\left.\mathrm{E}_{2}\right)$. Correlations with percent body fat change were somewhat weaker $\left(r_{\mathrm{s}}=0.13, P=0.01\right.$ for total $\mathrm{E}_{2} ; r_{\mathrm{s}}=0.08, P=0.12$ for estrone; $r_{\mathrm{s}}=-0.27, P<0.01$ for SHBG; $r_{\mathrm{s}}=0.17, P<0.01$ for free $E_{2}$ ). Change in waist circumference was significantly correlated with SHBG and free $\mathrm{E}_{2}$ changes (SHBG: $r_{\mathrm{s}}=-0.27, P<0.0001$; free $\left.\mathrm{E}_{2}: r_{\mathrm{s}}=0.14, P=0.007\right)$ but not total $\mathrm{E}_{2}\left(r_{\mathrm{s}}=0.09, P=0.09\right)$ or estrone $\left(r_{\mathrm{s}}=0.04, P=0.49\right)$. Similarly, changes in estimated $\mathrm{VO}_{2 \max }$ were weakly correlated with changes in SHBG $\left(r_{\mathrm{s}}=0.11, P=0.04\right)$ and free $\mathrm{E}_{2}\left(r_{\mathrm{s}}=-0.11, P=0.04\right)$ but not total $\mathrm{E}_{2}\left(r_{\mathrm{s}}=-0.09\right.$, $P=0.08)$ or estrone $\left(r_{\mathrm{s}}=0.02, P=0.64\right)$.

\section{Discussion}

On average, circulating concentrations of total $\mathrm{E}_{2}$, estrone, SHBG, and free $\mathrm{E}_{2}$ changed similarly over 12 months for women prescribed 150 or $300 \mathrm{~min} /$ week of aerobic exercise. Treatment effect ratios, representing the HIGH: MODERATE ratio of geometric mean biomarker levels over 12 months, were all null, providing no evidence of a dose

Published by Bioscientifica Ltd 
Table 5 Hormone concentrations at baseline and 12 months by quintile of exercise adherence ${ }^{\text {a }}$ for MODERATE and HIGH groups combined

\begin{tabular}{|c|c|c|c|c|c|c|c|c|c|}
\hline \multirow[b]{2}{*}{ Sex hormone } & \multicolumn{2}{|c|}{ Baseline } & \multicolumn{2}{|c|}{12 Months } & \multicolumn{2}{|c|}{12 Months:Baseline ${ }^{b}$} & \multirow[b]{2}{*}{$\begin{array}{l}\text { Percent } \\
\text { change }^{c}\end{array}$} & \multirow[b]{2}{*}{$\boldsymbol{P}_{\text {value }}{ }^{\mathrm{d}}$} & \multirow[b]{2}{*}{ P-trend ${ }^{\mathrm{e}}$} \\
\hline & $\begin{array}{c}\text { Geometric } \\
\text { mean }^{\mathrm{b}}\end{array}$ & $95 \% \mathrm{Cl}$ & $\begin{array}{c}\text { Geometric } \\
\text { mean }^{\mathrm{b}}\end{array}$ & $95 \% \mathrm{Cl}$ & $\begin{array}{l}\text { Geometric } \\
\text { mean ratio }\end{array}$ & $95 \% \mathrm{Cl}$ & & & \\
\hline \multicolumn{10}{|l|}{ Estradiol (pg/ml) } \\
\hline$\leq 110 \mathrm{~min} /$ week & 10.3 & $9.3,11.4$ & 10.8 & $9.8,12.0$ & 1.06 & $0.98,1.14$ & 5.2 & Ref & 0.002 \\
\hline 110-134 min/week & 9.6 & $8.8,10.5$ & 8.9 & $8.2,9.8$ & 0.93 & $0.88,0.99$ & -7.1 & 0.002 & \\
\hline 134-152 min/week & 10.2 & $9.3,11.2$ & 9.3 & $8.4,10.4$ & 0.92 & $0.86,0.99$ & -8.3 & 0.003 & \\
\hline 152-245 min/week & 9.4 & $8.6,10.3$ & 9.6 & $8.9,10.4$ & 1.02 & $0.94,1.1$ & 1.9 & 0.19 & \\
\hline$>245 \mathrm{~min} /$ week & 8.8 & $8.2,9.5$ & 7.8 & $7.2,8.4$ & 0.89 & $0.84,0.95$ & -11.0 & $<0.0001$ & \\
\hline \multicolumn{10}{|l|}{ Estrone (pg/ml) } \\
\hline$\leq 110 \mathrm{~min} /$ week & 40.5 & $37.5,43.7$ & 39.2 & $36.0,42.7$ & 0.97 & $0.91,1.03$ & -3.1 & Ref & 0.97 \\
\hline 110-134 min/week & 37.4 & $34.5,40.5$ & 35.8 & $33.0,38.8$ & 0.96 & $0.91,1.00$ & -4.4 & 0.40 & \\
\hline 134-152 min/week & 38.5 & $35.6,41.6$ & 38.6 & $35.6,41.8$ & 1.00 & $0.95,1.06$ & 0.3 & 0.51 & \\
\hline 152-245 min/week & 36.5 & $33.9,39.4$ & 37.3 & $34.7,40.1$ & 1.02 & $0.96,1.09$ & 2.0 & 0.43 & \\
\hline$>245 \mathrm{~min} /$ week & 34.6 & $32.4,37.0$ & 33.7 & $31.5,36.1$ & 0.97 & $0.93,1.02$ & -2.5 & 0.44 & \\
\hline \multicolumn{10}{|c|}{ Sex hormone binding globulin (nmol/l) } \\
\hline$\leq 110 \mathrm{~min} /$ week & 44.0 & $39.9,48.6$ & 47.0 & $42.4,52.2$ & 1.07 & $1.01,1.13$ & 6.9 & Ref & 0.37 \\
\hline 110-134 min/week & 44.6 & $40.5,49.2$ & 47.9 & $43.6,52.7$ & 1.07 & $1.02,1.13$ & 7.4 & 0.83 & \\
\hline 134-152 min/week & 42.2 & $38.4,46.4$ & 46.7 & $42.6,51.2$ & 1.11 & $1.06,1.16$ & 10.8 & 0.36 & \\
\hline 152-245 min/week & 48.5 & $43.5,54.1$ & 51.1 & $46.3,56.3$ & 1.05 & $1.01,1.09$ & 5.2 & 0.95 & \\
\hline$>245 \mathrm{~min} /$ week & 48.1 & $43.2,53.5$ & 52.7 & $47.6,58.3$ & 1.10 & $1.05,1.15$ & 9.5 & 0.26 & \\
\hline \multicolumn{10}{|l|}{ Free estradiol (pg/ml) } \\
\hline$\leq 110 \mathrm{~min} /$ week & 0.24 & $0.21,0.27$ & 0.25 & $0.22,0.28$ & 1.03 & $0.95,1.12$ & 2.7 & Ref & 0.002 \\
\hline 110-134 min/week & 0.22 & $0.2,0.25$ & 0.20 & $0.18,0.22$ & 0.91 & $0.86,0.96$ & -9.3 & 0.004 & \\
\hline 134-152 min/week & 0.24 & $0.22,0.27$ & 0.21 & $0.19,0.24$ & 0.89 & $0.83,0.96$ & -11.6 & 0.003 & \\
\hline 152-245 min/week & 0.21 & $0.19,0.23$ & 0.21 & $0.19,0.23$ & 1.00 & $0.93,1.09$ & 0.5 & 0.28 & \\
\hline$>245 \mathrm{~min} /$ week & 0.20 & $0.18,0.22$ & 0.17 & $0.15,0.19$ & 0.86 & $0.81,0.93$ & -13.7 & $<0.0001$ & \\
\hline
\end{tabular}

effect on circulating estrogen or SHBG concentrations. Exploratory analyses suggested our null findings may be partly adherence related and, possibly, that dose effects might vary with baseline BMI and when exercise is done mainly with vigorous intensity.

Compared with the ALPHA trial, which tested an exercise prescription of $225 \mathrm{~min} /$ week using similar methods and participants (Friedenreich et al. 2010), estrogen reductions in BETA were smaller on average (4-8\% in BETA vs $12-13 \%$ in ALPHA for free and total $\mathrm{E}_{2}$; $0-3 \%$ in BETA vs 5\% in ALPHA for estrone) and SHBG increases were slightly larger in BETA (6-10\% in BETA vs $3 \%$ in ALPHA). Similarly, other exercise trials in postmenopausal women typically improved these biomarker concentrations by $2-13 \%$ (Figueroa et al. 2003, Copeland \& Tremblay 2004, McTiernan et al. 2004, Orsatti et al. 2008, Monninkhof et al. 2009, Friedenreich et al. 2010, Yoo et al. 2010, Campbell et al. 2012, Kim \& Kim 2012).
Thus, despite the relatively high exercise prescription in BETA, we could not demonstrate greater estrogen or SHBG changes than reported previously in similar trials. The reasons for this finding are unclear but might relate to modest adherence, particularly in the high volume group.

Epidemiologic research has generally shown that exercise-induced changes in estrogen concentrations are attributable to weight loss in postmenopausal women (Friedenreich et al. 2011, Campbell et al. 2012, Stolzenberg-Solomon et al. 2012, Jones et al. 2013). Adipose tissue becomes a major site of estrone and $\mathrm{E}_{2}$ biosynthesis after menopause via aromatase activity (Folkerd \& Dowsett 2013, Kinoshita et al. 2014), and consequently, BMI relates positively to circulating $\mathrm{E}_{2}$ and estrone concentrations (Endogenous Hormones and Breast Cancer Collaborative Group 2015). Furthermore, BMI is inversely related to SHBG concentrations

Published by Bioscientifica Ltd. 
Table 6 Changes in endogenous estrogen and SHBG concentrations over 12 months in adherent women ${ }^{\text {a }}$ stratified by time at target intensity; the BETA trial, Alberta, Canada, 2010-2013

\begin{tabular}{|c|c|}
\hline Biomarker & \\
\hline $\begin{array}{l}\text { Proportion of time at } \\
\text { high intensity } \\
\text { (average } \mathrm{min} / \text { week) }^{\mathrm{d}}\end{array}$ & $\begin{array}{l}\text { Prescribed } \\
\text { exercise } \\
\text { duration }\end{array}$ \\
\hline \multicolumn{2}{|l|}{ Estradiol (pg/ml) } \\
\hline$<60 \%$ prescribed & $\begin{array}{l}\text { MODERATE } \\
\text { HIGH }\end{array}$ \\
\hline$\geq 60 \%$ prescribed & $\begin{array}{l}\text { MODERATE } \\
\text { HIGH }\end{array}$ \\
\hline \multicolumn{2}{|l|}{ Estrone (pg/ml) } \\
\hline$<60 \%$ prescribed & $\begin{array}{l}\text { MODERATE } \\
\text { HIGH }\end{array}$ \\
\hline$\geq 60 \%$ prescribed & $\begin{array}{l}\text { MODERATE } \\
\mathrm{HIGH}\end{array}$ \\
\hline \multicolumn{2}{|l|}{ SHBG (nmol/l) } \\
\hline$<60 \%$ prescribed & $\begin{array}{l}\text { MODERATE } \\
\text { HIGH }\end{array}$ \\
\hline$\geq 60 \%$ prescribed & $\begin{array}{l}\text { MODERATE } \\
\text { HIGH }\end{array}$ \\
\hline \multicolumn{2}{|c|}{ Free estradiol $(\mathrm{pg} / \mathrm{ml})$} \\
\hline$<60 \%$ prescribed & $\begin{array}{l}\text { MODERATE } \\
\mathrm{HIGH}\end{array}$ \\
\hline$\geq 60 \%$ prescribed & $\begin{array}{l}\text { MODERATE } \\
\text { HIGH }\end{array}$ \\
\hline
\end{tabular}

\begin{tabular}{|c|c|}
\hline$n$ & $\begin{array}{c}6 \text { month percent } \\
\text { change from } \\
\text { baseline }\end{array}$ \\
\hline 17 & -13.4 \\
\hline 44 & -0.8 \\
\hline 40 & 5.2 \\
\hline 34 & -1.0 \\
\hline 17 & -7.5 \\
\hline 44 & 2.2 \\
\hline 40 & 3.2 \\
\hline 34 & 3.2 \\
\hline 17 & 10.4 \\
\hline 44 & 10.4 \\
\hline 40 & 4.3 \\
\hline 34 & 9.7 \\
\hline 17 & -16.0 \\
\hline 44 & -4.4 \\
\hline 40 & 3.6 \\
\hline 34 & -4.0 \\
\hline
\end{tabular}

\begin{tabular}{|c|c|c|c|}
\hline \multirow{2}{*}{$\begin{array}{l}12 \text { month } \\
\text { percent change } \\
\text { from baseline }\end{array}$} & \multicolumn{2}{|c|}{ Treatment effect $^{\mathbf{b}}$} & \multirow[b]{2}{*}{$\begin{array}{l}\text { Between- } \\
\text { group } P^{c}\end{array}$} \\
\hline & $\begin{array}{c}\text { Ratio of } \\
\text { HIGH:MOD }\end{array}$ & $95 \% \mathrm{Cl}$ & \\
\hline $\begin{array}{l}-14.9 \\
-10.1\end{array}$ & 1.07 & $0.96,1.20$ & 0.23 \\
\hline $\begin{array}{r}-2.3 \\
-11.2\end{array}$ & 0.88 & $0.79,0.99$ & 0.03 \\
\hline $\begin{array}{l}-8.6 \\
-4.0\end{array}$ & 1.09 & $1.00,1.18$ & 0.06 \\
\hline $\begin{array}{l}-2.7 \\
-1.1\end{array}$ & 0.99 & $0.91,1.07$ & 0.74 \\
\hline $\begin{array}{l}9.5 \\
9.0\end{array}$ & 1.00 & $0.90,1.11$ & 0.93 \\
\hline $\begin{array}{r}10.3 \\
8.9\end{array}$ & 1.04 & $0.97,1.13$ & 0.27 \\
\hline $\begin{array}{l}-17.2 \\
-12.9\end{array}$ & 1.07 & $0.95,1.21$ & 0.26 \\
\hline $\begin{array}{r}-5.6 \\
-13.5\end{array}$ & 0.86 & $0.77,0.97$ & 0.01 \\
\hline
\end{tabular}

ancluded $n=135$ women for whom, across weeks 13-52 (at full prescription), average adherence in the exercise logs was 90-100\% in the MODERATE group $(135-150 \mathrm{~min} /$ week; $n=57$ ) or $\geq 90 \%$ in the HIGH group ( $\geq 270 \mathrm{~min} /$ week; $n=78$ ).

${ }^{b}$ HIGH:MODERATE ratio of geometric means for biomarker levels over 12 months adjusted for biomarker level at baseline. A ratio $<1.0$ indicates lower biomarker concentrations in the HIGH exercise group at 6 and 12 months; a ratio $>1.0$ indicates lower biomarker concentrations in the MODERATE exercise group; a ratio equal to 1.0 indicates no difference in biomarker concentrations between the HIGH and MODERATE exercise groups.

${ }^{c} P$ for testing the HIGH-MODERATE group difference over 12 months from the linear mixed model, adjusted for biomarker level at baseline.

${ }^{\mathrm{d}}$ Time at high intensity was defined as time exercising at an intensity of $60-80 \%$ heart rate reserve averaged for each participant over 52 weeks. Cut points for the stratified analysis were $60 \%$ of the prescribed durations, i.e., $90 \mathrm{~min} /$ week in the MODERATE group and $180 \mathrm{~min} /$ week in the HIGH group.

(Endogenous Hormones and Breast Cancer Collaborative Group et al. 2011, Goto et al. 2014), which restrict $\mathrm{E}_{2}$ bioavailability through SHBG binding (our analysis of free $\mathrm{E}_{2}$ therefore reflects the bioavailable portion). The significant correlations we observed in BETA between $\mathrm{E}_{2}$ and body weight changes, and between SHBG and changes in body weight and waist circumference, are consistent with a mediating role for adiposity. For unknown reasons, adiposity correlations were not found with estrone.

It is unclear, then, why we did not find significant dose effects despite greater fat loss with the $300 \mathrm{~min} /$ week prescription (Table 2). It is possible that because the magnitude of the difference in fat loss between the two groups was rather low ( $\sim 1 \%$ difference between groups with respect to total fat loss), there were limited effects on sex hormones. Similarly, there may have been insufficiently large group differences with respect to other mediating factors besides adiposity, e.g., insulin mediating SHBG levels (Pugeat et al. 1991). Another explanation relates to hemodilution of sex hormone concentrations in obesity (Grubb et al. 2009, Yang et al. 2011). If the body surface area was decreased through weight loss in our trial, then decreased vascular volume would manifest through increased sex hormone concentrations, thereby confounding our primary analysis. However, a sensitivity analysis based on biomarker mass made essentially no difference in our primary results or in our stratified analyses of obese women.

There may also have been effect modification. For instance, our finding of stronger SHBG increases with the $300 \mathrm{~min} /$ week prescription in obese women might reflect the stronger reductions in subcutaneous abdominal fat we observed in this subgroup (Friedenreich et al. 2015), which could mediate SHBG changes (Liedtke et al. 2012). We cannot explain why greater SHBG increases occurred with the $150 \mathrm{~min} /$ week prescription in non-obese women, which was unexpected, but this effect was diminished in the per-protocol sample (data not shown). Results stratified by time in zone suggested an enhanced dose effect on

Published by Bioscientifica Ltd. 
$\mathrm{E}_{2}$ when most of the prescribed exercise was done at high intensity. However, the dose effect seemed to be due to relatively small $\mathrm{E}_{2}$ changes in women who exercised for a moderate duration (135-150 min/week) at mainly high intensity ( $\geq 112 \mathrm{~min} /$ week) for reasons that are unclear. Perhaps exercise compensation was more common in this subgroup. With regard to estrone, the modest changes observed in BETA and the lack of dose dependency, as in the ALPHA trial (Friedenreich et al. 2010), overall do not support a dose-response relation between estrone and our exercise prescriptions. An important limitation of our trial was that the statistical power for assessing the efficacy of $300 \mathrm{~min} /$ week aerobic exercise was lower than planned because some women exercised below this level. Sensitivity analyses to account for non-adherence indeed revealed slightly stronger dose-response trends for total and free $\mathrm{E}_{2}$ changes (Tables 4 and 5) suggesting that significant dose effects might have been found if more women assigned to the high volume group had exercised $>245 \mathrm{~min} /$ week. Still, 12-month $\mathrm{E}_{2}$ changes even at the highest levels of adherence were modest $(<14 \%)$. Furthermore, we acknowledge the key limitations of our perprotocol analyses - namely, selection bias and lower statistical power. Finally, the generalizability of our results may be limited to healthy postmenopausal women with BMI $22-40 \mathrm{~kg} / \mathrm{m}^{2}$, who are non-users of exogenous hormones and physically inactive but highly motivated to exercise.

To our knowledge, BETA is the largest dose-response exercise trial designed to inform postmenopausal breast cancer prevention. In previous dose-response RCTs, exercise prescriptions did not target primary cancer prevention, few breast cancer biomarkers were assessed, and only some (Asikainen et al. 2002, Asikainen et al. 2003, Morss et al. 2004, Dalleck et al. 2009) studied postmenopausal women exclusively. The dose-response to Exercise in Women trial (Morss et al. 2004, Church et al. 2009) was a large RCT statistically powered to compare exercise durations in over 450 postmenopausal women. However, lower volumes of exercise were prescribed than in BETA (50\% $\mathrm{VO}_{2 \max }$ for approximately 75,140 , and $190 \mathrm{~min} /$ week) and sex hormones were not assessed. BETA was a long-term intervention trial that was tightly controlled (Friedenreich et al. 2014) and study retention was exceptionally good with a $3.5 \%$ dropout rate overall. Furthermore, our extraction-based assays for quantifying estrone and $\mathrm{E}_{2}$ in serum were sensitive and specific (Endogenous Hormones and Breast Cancer Collaborative Group 2015).
In conclusion, our intention-to-treat analysis provided no evidence of a difference, with respect to endogenous estrogen or SHBG changes, in prescribing 300 vs $150 \mathrm{~min} /$ week of moderate-vigorous aerobic exercise to inactive postmenopausal women. For some individuals, dietary modification may be more feasible than increasing exercise volume for the purpose of lowering endogenous estrogen concentrations. For instance, one previous RCT in 439 overweight/obese postmenopausal women showed that free $\mathrm{E}_{2}$ concentrations were decreased by $\sim 5 \%$ on average in women prescribed 12 months of aerobic exercise, vs $26 \%$ in women prescribed exercise and a reduced-calorie diet (Campbell et al. 2012). Still, higher (vs lower) volumes of aerobic exercise offer important benefits for many other facets of postmenopausal health including physical fitness, cardiovascular and cognitive health, and overall survival (Church et al. 2007, Swift et al. 2012, Anderson et al. 2014). Furthermore, $300 \mathrm{~min} /$ week of aerobic exercise may be superior to $150 \mathrm{~min} /$ week for lowering breast cancer risk through other biologic pathways besides sex hormones, for example, insulin sensitivity and chronic low-grade inflammation (Rose \& Vona-Davis 2014). Future analyses from BETA will address this question. The effects of exercise on myokines (Hojman et al. 2011), immune function, oxidative stress, telomere length and DNA methylation have been understudied in the context of breast cancer risk (Neilson et al. 2014) and could also be examined in future exercise trials.

\section{Declaration of interest}

The authors declare that there is no conflict of interest that could be perceived as prejudicing the impartiality of the research reported.

\section{Funding}

Research relating to this analysis was funded by a research grant from the Alberta Cancer Foundation (\#24404). Dr C M Friedenreich holds a Health Senior Scholar Award from Alberta Innovates-Health Solutions and the Alberta Cancer Foundation Weekend to End Women's Cancers Breast Cancer Chair. Drs K S Courneya and Y Yasui are supported by the Canada Research Chairs Program. ClinicalTrials.gov Registration Number: NCT01435005.

Author contribution statement

Study design and funding: C M Friedenreich, K S Courneya, F Z Stanczyk, Y Yasui, A Duha. Study conduct: Friedenreich, Courneya, Stanczyk, Duha, MacLaughlin, Kallal, Forbes. Data management: C M Friedenreich, S MacLaughlin, C Kallal, Q Wang. Data analysis: Q Wang, H K Neilson, C M Friedenreich. Data interpretation: C M Friedenreich, K S Courneya, Y Yasui, H K Neilson, Q Wang, C Kallal, C C Forbes. Manuscript writing:

Published by Bioscientifica Ltd. 
H K Neilson, C M Friedenreich, K S Courneya. Manuscript review and approval: All authors

\begin{abstract}
Acknowledgements
Calgary Study Coordinators were Krista Carlson, Sana Fakih, Megan Farris, Quinn Harris, Erica Roberts, and Kristen Simone. Edmonton Study Coordinators were Natalie Ilkiw, and Dr Amy Speed Andrews. Assistance with information sessions was provided in Calgary by Drs Brigid Lynch and Fabiola Aparicio-Ting. Calgary Exercise Trainers were Carrie Anderson, Alia Bharwani, Shannon Brown, Ashley Cuthbert, Sue Daniel, Julie Gowans, Margo Graham, Erin Korsbrek, Kathleen Kranenburg, Jessica Morrison, Jason Ng, Nicole Slot, Tania White, and Kaila Wright. Edmonton Exercise Trainers were Arne Anderson, Lisa Belanger, Jennifer Crawford, Cindy Forbes, Alyssa Hindle, Corey Kuzik, Erin McGowan, Mary Norris, Janel Park, Julianne Symons, Linda Trinh, Stephanie Voaklander and Lynne Wong. Study recruiters were Jennie Duke, Jasdeep Hayer, Trisha Kelly, Jasmine Lee, and Lilly Mah. Data entry was done by Sinead Boyle, Barbara Mercer, Carla Quesnel and Trish Kelly. Biospecimen support was provided by Catherine Munro. Data management, including database creation, questionnaire design, data integrity and quality control, was done by Dr Steven Szarka, Farit Vakhetov, Wendy Walroth and Rachel O'Reilly.
\end{abstract}

\section{References}

Ainsworth BE, Haskell WL, Herrmann SD, Meckes N, Bassett DR Jr, Tudor-Locke C, Greer JL, Vezina J, Whitt-Glover MC \& Leon AS 2011 Compendium of physical activities: a second update of codes and MET values. Medicine and Science in Sports and Exercise 43 1575-1581. (doi:10.1249/MSS.0b013e31821ece12)

American College of Sports Medicine 2000 ACSM's Guidelines for Exercise Testing and Prescription. Philadelphia, PA: Lippincott Williams \& Wilkins.

Anderson D, Seib C \& Rasmussen L 2014 Can physical activity prevent physical and cognitive decline in postmenopausal women? A systematic review of the literature Maturitas 79 14-33. (doi:10.1016/ j.maturitas.2014.06.010)

Asikainen TM, Miilunpalo S, Oja P, Rinne M, Pasanen M, Uusi-Rasi K \& Vuori I 2002 Randomised, controlled walking trials in postmenopausal women: the minimum dose to improve aerobic fitness? British Journal of Sports Medicine 36 189-194. (doi:10.1136/bjsm.36.3.189)

Asikainen TM, Miilunpalo S, Kukkonen-Harjula K, Nenonen A, Pasanen M, Rinne M, Uusi-Rasi K, Oja P \& Vuori I 2003 Walking trials in postmenopausal women: effect of low doses of exercise and exercise fractionization on coronary risk factors. Scandinavian Journal of Medicine \& Science in Sports 13 284-292. (doi:10.1034/j.1600-0838.2003. 00331.x)

Borg G 1998 Borg's Perceived Exertion and Pain Scales. Champaign, IL, USA: Human Kinetics.

Campbell KL, Foster-Schubert KE, Alfano CM, Wang CC, Wang CY, Duggan CR, Mason C, Imayama I, Kong A, Xiao L et al. 2012 Reduced-calorie dietary weight loss, exercise, and sex hormones in postmenopausal women: randomized controlled trial. Journal of Clinical Oncology 30 2314-2326. (doi:10.1200/JCO.2011.37.9792)

Canadian Society for Exercise Physiology 2003 The Canadian Physical Activity, Fitness and Lifestyle Approach (CPAFLA): CSEP - Health and Fitness Program's Health-Related Appraisal and Counselling Strategy. Ottawa, ON, USA: Canadian Society for Exercise Physiology.

Canadian Society for Exercise Physiology 2011 Canadian Physical Activity Guidelines for Adults - 18-64 years. Ottowa, ON, Canada: Canadian Society for Exercise Physiology. (available at: www.csep.ca/ guidelines)
Church TS, Earnest CP, Skinner JS \& Blair SN 2007 Effects of different doses of physical activity on cardiorespiratory fitness among sedentary, overweight or obese postmenopausal women with elevated blood pressure: a randomized controlled trial. Journal of the American Medical Association 297 2081-2091. (doi:10.1001/jama.297.19.2081)

Church TS, Martin CK, Thompson AM, Earnest CP, Mikus CR \& Blair SN 2009 Changes in weight, waist circumference and compensatory responses with different doses of exercise among sedentary, overweight postmenopausal women. PLOS ONE 4 e4515. (doi:10.1371/journal. pone.0004515)

Copeland JL \& Tremblay MS 2004 Effect of HRT on hormone responses to resistance exercise in post-menopausal women. Maturitas 48 360-371. (doi:10.1016/j.maturitas.2003.09.025)

Csizmadi I, Kahle L, Ullman R, Dawe U, Zimmerman T, Friedenreich CM, Bryant HE \& Subar A 2007 Adaptation and evaluation of the National Cancer Institute's Dietary History Questionnaire and nutrient database for use in Canadian Populations. Public Health Nutrition 10 88-96. (doi:10.1017/S1368980007184287)

Dalleck LC, Allen BA, Hanson BA, Borresen EC, Erickson ME \& De Lap SL 2009 Dose-response relationship between moderate-intensity exercise duration and coronary heart disease risk factors in postmenopausal women. Journal of Women's Health 18 105-113. (doi:10.1089/ jwh.2008.0790)

Endogenous Hormones and Breast Cancer Collaborative Group 2015 Steroid hormone measurements from different types of assays in relation to body mass index and breast cancer risk in postmenopausal women: Reanalysis of eighteen prospective studies. Steroids 99 49-55. (doi:10.1016/j.steroids.2014.09.001)

Endogenous Hormones and Breast Cancer Collaborative Group XX, Key TJ, Appleby PN, Reeves GK, Roddam AW, Helzlsouer KJ, Alberg AJ, Rollison DE, Dorgan JF \& Brinton LA 2011 Circulating sex hormones and breast cancer risk factors in postmenopausal women: reanalysis of 13 studies. British Journal of Cancer 105 709-722. (doi:10.1038/bjc. 2011.254)

Figueroa A, Going SB, Milliken LA, Blew RM, Sharp S, Teixeira PJ \& Lohman TG 2003 Effects of exercise training and hormone replacement therapy on lean and fat mass in postmenopausal women. Journals of Gerontology. Series A, Biological Sciences and Medical Sciences 58 M266-M270. (doi:10.1093/gerona/58.3.M266)

Folkerd E \& Dowsett M 2013 Sex hormones and breast cancer risk and prognosis. Breast 22 (Suppl 2) S38-S43. (doi:10.1016/j.breast. 2013.07.007)

Friedenreich CM, Courneya KS, Neilson HK, Matthews CE, Willis G, Irwin M, Troiano R \& Ballard-Barbash R 2006 Reliability and validity of the past year total physical activity questionnaire. American Journal of Epidemiology 163 959-970. (doi:10.1093/aje/kwj112)

Friedenreich CM, Woolcott CG, McTiernan A, Ballard-Barbash R, Brant RF, Stanczyk FZ, Terry T, Boyd NF, Yaffe MJ, Irwin ML et al. 2010 Alberta physical activity and breast cancer prevention trial: sex hormone changes in a year-long exercise intervention among postmenopausal women. Journal of Clinical Oncology 28 1458-1466. (doi:10.1200/JCO. 2009.24.9557)

Friedenreich CM, Neilson HK, Woolcott CG, Wang Q, Yasui Y, Brant RF, Stanczyk FZ, Campbell KL \& Courneya KS 2011 Mediators and moderators of the effects of a year-long exercise intervention on endogenous sex hormones in postmenopausal women. Cancer Causes \& Control 22 1365-1373. (doi:10.1007/s10552-011-9809-5)

Friedenreich CM, MacLaughlin S, Neilson HK, Stanczyk FZ, Yasui Y, Duha A, Lynch BM, Kallal C \& Courneya KS 2014 Study design and methods for the breast cancer and exercise trial in Alberta (BETA). BMC Cancer 14919. (doi:10.1186/1471-2407-14-919)

Friedenreich CM, Neilson HK, O'Reilly R, Duha A, Yasui Y, Morielli AR, Adams SC \& Courneya KS 2015 Effects of a high versus moderate volume of aerobic exercise on adiposity outcomes in postmenopausal women: a randomized clinical trial. JAMA Oncology [in press]. (doi:10.1001/jamaoncol.2015.2239) 
Goto A, Chen BH, Song Y, Cauley J, Cummings SR, Farhat GN, Gunter M, Van Horn L, Howard BV, Jackson R et al. 2014 Age, body mass, usage of exogenous estrogen, and lifestyle factors in relation to circulating sex hormone-binding globulin concentrations in postmenopausal women. Clinical Chemistry 60 174-185. (doi:10.1373/ clinchem.2013.207217)

Grubb RL III, Black A, Izmirlian G, Hickey TP, Pinsky PF, Mabie JE, Riley TL, Ragard LR, Prorok PC, Berg CD et al. 2009 Serum prostate-specific antigen hemodilution among obese men undergoing screening in the prostate, lung, colorectal, and ovarian cancer screening trial. Cancer Epidemiology, Biomarkers \& Prevention 18 748-751. (doi:10.1158/ 1055-9965.EPI-08-0938)

Hastert TA, Beresford SAA, Patterson RE, Kristal AR \& White E 2013 Adherence to WCRF/AICR cancer prevention recommendations and risk of postmenopausal breast cancer. Cancer Epidemiology, Biomarkers \& Prevention 22 1498-1508. (doi:10.1158/1055-9965. EPI-13-0210)

Hojman P, Dethlefsen C, Brandt C, Hansen J, Pedersen L \& Pedersen BK 2011 Exercise-induced muscle-derived cytokines inhibit mammary cancer cell growth. American Journal of Physiology. Endocrinology and Metabolism 301 E504-E510. (doi:10.1152/ajpendo. 00520.2010)

James RE, Lukanova A, Dossus L, Becker S, Rinaldi S, Tjonneland A, Olsen A, Overvad K, Mesrine S, Engel P et al. 2011 Postmenopausal serum sex steroids and risk of hormone receptor-positive and -negative breast cancer: a nested case-control study. Cancer Prevention Research 4 1626-1635. (doi:10.1158/1940-6207.CAPR-11-0090)

Jones ME, Schoemaker M, Rae M, Folkerd EJ, Dowsett M, Ashworth A \& Swerdlow AJ 2013 Changes in estradiol and testosterone levels in postmenopausal women after changes in body mass index. Journal of Clinical Endocrinology and Metabolism 98 2967-2974. (doi:10.1210/ jc.2013-1588)

Key T, Appleby P, Barnes I \& Reeves G 2002 Endogenous sex hormones and breast cancer in postmenopausal women: reanalysis of nine prospective studies. Journal of the National Cancer Institute 94 606-616. (doi:10.1093/jnci/94.8.606)

Kim JW \& Kim DY 2012 Effects of aerobic exercise training on serum sex hormone binding globulin, body fat index, and metabolic syndrome factors in obese postmenopausal women. Metabolic Syndrome and Related Disorders 10 452-457. (doi:10.1089/met.2012.0036)

Kinoshita T, Honma S, Shibata Y, Yamashita K, Watanabe Y, Maekubo H, Okuyama M, Takashima A \& Takeshita N 2014 An innovative LC-MS/MS-based method for determining CYP 17 and CYP 19 activity in the adipose tissue of pre- and postmenopausal and ovariectomized women using 13C-labeled steroid substrates. Journal of Clinical Endocrinology and Metabolism 99 1339-1347. (doi:10.1210/jc. 2013-3715)

Kushi LH, Doyle C, McCullough M, Rock CL, Demark-Wahnefried W, Bandera EV, Gapstur S, Patel AV, Andrews K \& Gansler T 2012 American Cancer Society Guidelines on nutrition and physical activity for cancer prevention: reducing the risk of cancer with healthy food choices and physical activity. CA: A Cancer Journal for Clinicians 62 30-67. (doi:10.3322/caac.20140)

Liedtke S, Schmidt ME, Vrieling A, Lukanova A, Becker S, Kaaks R, Zaineddin AK, Buck K, Benner A, Chang-Claude J et al. 2012 Postmenopausal sex hormones in relation to body fat distribution. Obesity 20 1088-1095. (doi:10.1038/oby.2011.383)

McTiernan A, Tworoger SS, Ulrich CM, Yasui Y, Irwin ML, Rajan KB, Sorensen B, Rudolph RE, Bowen D, Stanczyk FZ et al. 2004 Effect of exercise on serum estrogens in postmenopausal women: a 12-month randomized clinical trial. Cancer Research 64 2923-2928. (doi:10.1158/ 0008-5472.CAN-03-3393)

Monninkhof EM, Velthuis MJ, Peeters PH, Twisk JW \& Schuit AJ 2009 Effect of exercise on postmenopausal sex hormone levels and role of body fat: a randomized controlled trial. Journal of Clinical Oncology $\mathbf{2 7}$ 4492-4499. (doi:10.1200/JCO.2008.19.7459)
Morss GM, Jordan AN, Skinner JS, Dunn AL, Church TS, Earnest CP, Kampert JB, Jurca R \& Blair SN 2004 Dose response to exercise in women aged 45-75 yr (DREW): design and rationale. Medicine and Science in Sports and Exercise 36 336-344. (doi:10.1249/01.MSS. 0000113738.06267.E5)

National Institutes of Health XX 1998 Executive summary: clinical guidelines on the identification, evaluation, and treatment of overweight and obesity in adults - the evidence report. Obesity Research 6 (Suppl 2) 51S-209S. (doi:10.1002/j.1550-8528.1998.tb00690.x)

Neilson HK, Conroy SM \& Friedenreich CM 2014 The influence of energetic factors on biomarkers of postmenopausal breast cancer risk. Current Nutrition Reports 3 22-34. (doi:10.1007/s13668-013-0069-8)

Orsatti FL, Nahas EAP, Maesta N, Nahas-Neto J \& Burini RC 2008 Plasma hormones, muscle mass and strength in resistance-trained postmenopausal women. Maturitas 59 394-404. (doi:10.1016/j. maturitas.2008.04.002)

Pearson TC, Guthrie DL, Simpson J, Chinn S, Barosi G, Ferrant A, Lewis SM \& Najean Y 1995 Interpretation of measured red cell mass and plasma volume in adults: expert panel on radionuclides of the International Council for Standardization in Haematology. British Journal of Haematology 89 748-756. (doi:10.1111/j.1365-2141.1995.tb08411.x)

Pollock ML, Foster C, Schmidt D, Hellman C, Linnerud AC \& Ward A 1982 Comparative analysis of physiologic responses to three different maximal graded exercise test protocols in healthy women. American Heart Journal 103 363-373. (doi:10.1016/0002-8703 (82)90275-7)

Pugeat M, Crave JC, Elmidani M, Nicolas MH, Garoscio-Cholet M, Lejeune H, Dechaud H \& Tourniaire J 1991 Pathophysiology of sex hormone binding globulin (SHBG): relation to insulin. Journal of Steroid Biochemistry and Molecular Biology 40 841-849. (doi:10.1016/ 0960-0760(91)90310-2)

R Core Team 2010 R: A Language and Environment for Statistical Computing. Version 2.11. Vienna: R Foundation for Statistical Computing.

Rose DP \& Vona-Davis L 2014 Biochemical and molecular mechanisms for the association between obesity, chronic Inflammation, and breast cancer. Biofactors 40 1-12. (doi:10.1002/biof.1109)

Rosner B 2011 Hypothesis testing: two-sample inference. In Fundamentals of Biostatistics, 7th edn, Boston, MA, USA: Brooks/Cole.

Rundle A 2005 Molecular epidemiology of physical activity and cancer. Cancer Epidemiology, Biomarkers \& Prevention 14 227-236. (doi:10.1158/ 1055-9965.EPI-04-0860)

Stolzenberg-Solomon RZ, Falk RT, Stanczyk F, Hoover RN, Appel LJ, Ard JD, Batch BC, Coughlin J, Han X, Lien LF et al. 2012 Sex hormone changes during weight loss and maintenance in overweight and obese postmenopausal African-American and non-African-American women. Breast Cancer Research 14 R141. (doi:10.1186/bcr3346)

Suzuki R, Orsini N, Saji S, Key TJ \& Wolk A 2009 Body weight and incidence of breast cancer defined by estrogen and progesterone receptor status-a meta-analysis. International Journal of Cancer $\mathbf{1 2 4}$ 698-712. (doi:10.1002/ijc.23943)

Swift DL, Earnest CP, Katzmarzyk PT, Rankinen T, Blair SN \& Church TS 2012 The effect of different doses of aerobic exercise training on exercise blood pressure in overweight and obese postmenopausal women. Menopause 19 503-509. (doi:10.1097/gme. 0b013e318238ea66)

Tworoger SS, Rosner BA, Willett WC \& Hankinson SE 2011 The combined influence of multiple sex and growth hormones on risk of postmenopausal breast cancer: a nested case-control study. Breast Cancer Research 13 R99. (doi:10.1186/bcr3040)

Tworoger SS, Zhang X, Eliassen AH, Qian J, Colditz GA, Willett WC, Rosner BA, Kraft P \& Hankinson SE 2014 Inclusion of endogenous hormone levels in risk prediction models of postmenopausal breast cancer. Journal of Clinical Oncology 32 3111-3117. (doi:10.1200/JCO. 2014.56.1068)

Published by Bioscientifica Ltd. 
Woolcott CG, Shvetsov YB, Stanczyk FZ, Wilkens LR, White KK, Caberto C, Henderson BE, Le Marchand L, Kolonel LN \& Goodman MT 2010 Plasma sex hormone concentrations and breast cancer risk in an ethnically diverse population of postmenopausal women: the Multiethnic Cohort Study. Endocrine-Related Cancer 17 125-134. (doi:10.1677/ERC-09-0211)

World Cancer Research Fund/American Institute for Cancer Research 2007 Food, Nutrition, Physical Activity, and the Prevention of Cancer: a Global Perspective. Washington, DC: AICR.

World Cancer Research Fund/American Institute for Cancer Research 2010 Continuous Update Project Report. Food, Nutrition, Physical Activity, and the Prevention of Breast Cancer. Washington, DC: AICR.

World Health Organization 2011 Recommended population levels of physical activity for health. In Global recommendations on physical activity for health, pp 15-34. Geneva, Switzerland: World Health Organization. (available at: www.who.int/dietphysicalactivity/ publications/9789241599979/en/)
Wu Y, Zhang D \& Kang S 2013 Physical activity and risk of breast cancer: a meta-analysis of prospective studies. Breast Cancer Research and Treatment 137 869-882. (doi:10.1007/ s10549-012-2396-7)

Yang HP, Black A, Falk RT, Brinton LA, Potischman N, Wentzensen N, Faupel-Badger JM \& Sherman ME 2011 Association of serum sex steroid hormone hemodilution and body mass index among healthy postmenopausal women. Annals of Epidemiology 21 466-471. (doi:10.1016/ j.annepidem.2011.01.003)

Yoo EJ, Jun TW \& Hawkins S 2010 The effects of a walking exercise program on fall-related fitness, bone metabolism, and fall-related psychological factors in elderly women. Research in Sports Medicine 18 236-250. (doi:10.1080/15438627.2010.510098)

Zhang X, Tworoger SS, Eliassen AH \& Hankinson SE 2013 Postmenopausal plasma sex hormone levels and breast cancer risk over 20 years of follow-up. Breast Cancer Research and Treatment 137 883-892. (doi:10.1007/s10549-012-2391-z)

Received in final form 14 July 2015

Accepted 7 August 2015
Published by Bioscientifica Ltd. 